\title{
Communication
}

Clayton D Delancey, Kamal Islam*, Gunnar R Kramer, Garrett J MacDonald, Alexander R Sharp, Brandon M Connare

\section{Geolocators reveal migration routes, stopover sites, and nonbreeding dispersion in a population of Cerulean Warblers}

https://doi.org/10.1515/ami-2020-0003

Received December 6, 2019; accepted February 24, 2020

\begin{abstract}
Cerulean Warblers (Setophaga cerulea) are among the fastest declining Nearctic-Neotropical migrant wood-warblers (Parulidae) in North America. Despite ongoing conservation efforts, little is known about their non-breeding distribution. In June 2016-2018, we deployed geolocators $(n=30)$ on adult male Cerulean Warblers in Indiana, USA, to track annual movements of individuals. Recovered geolocators $(n=4)$ showed that Cerulean Warblers occurred broadly throughout northern South America. Autumn migration lasted 44-71 days ( $n=$ $4)$, whereas spring migration lasted 37-41 days $(n=3)$. The average migration distance was $5268 \mathrm{~km}$. During autumn migration, Cerulean Warblers made 1-4 stopovers (i.e., $\geq 2$ days; $n=4)$ and $1-2$ stopovers during spring migration ( $n$ = 3). When crossing the Gulf of Mexico during autumn migration, two birds stopped over after crossing, but not beforehand. Two others navigated through the Caribbean rather than crossing the Gulf of Mexico. During spring migration, one individual stopped after crossing, one individual stopped before crossing, and one individual stopped before and after crossing the Gulf of Mexico. No birds migrated through the Caribbean Islands during spring migration. These results represent novel information describing annual movements of individual Cerulean Warblers and will inform conservation efforts for this declining species.
\end{abstract}

Keywords: full annual cycle, migratory connectivity, Setophaga cerulea

\footnotetext{
*Corresponding author: Kamal Islam, Ball State University, Muncie, IN United States, E-mail: kislam@bsu.edu Clayton D Delancey, Garrett J MacDonald, Alexander R Sharp, Brandon M Connare, Ball State University, Muncie, IN United States Gunnar R Kramer, University of Toledo, Toledo, $\mathrm{OH}$ United States
}

\section{Introduction}

Identifying the geographic distribution and assortment of migratory individuals during migration and nonbreeding periods is critical for understanding population trends [1]. Populations may be limited by factors occurring outside the breeding period including along population-specific migratory routes [2] or at nonbreeding areas [3]. Until recently, there has been a dearth of information on the nonbreeding dispersion and migratory behaviors of most species of New World wood-warblers (Parulidae). Most parulids migrate considerable distances between Nearctic breeding grounds and Neotropical nonbreeding grounds [4], and many of these species are declining [5]. The recent miniaturization of tracking technology (light-level geolocators) has made tracking small migratory species (< $10 \mathrm{~g}$ ) possible [6-8].

Cerulean Warblers (Setophaga cerulea) are small ( 9 g), Nearctic-Neotropical migratory songbirds that breed in mature deciduous forests of the eastern United States and adjacent southern Canada. Individuals overwinter in northern South America along the eastern slopes of the northern Andes at elevations of 500$2000 \mathrm{~m}$ [9]. Cerulean Warblers are among the fastest declining Nearctic-Neotropical migrant wood-warbler species in North America ( 3\% per year) [9] with declines purportedly linked to extensive habitat loss on both breeding and nonbreeding grounds [9, 10]. However, because Cerulean Warbler research, conservation, and management are focused on the breeding grounds, there is currently little information on the dispersion of Cerulean Warbler populations outside of the breeding period (i.e., stopovers during autumn and spring migrations, and the nonbreeding period), which may be hindering conservation efforts if limiting factors are experienced away from the breeding grounds [3]. Determining where populations of Cerulean Warblers overwinter, the routes they use to migrate between breeding and nonbreeding 
sites, and the level of within-population variation will aid in the identification of important areas where focused conservation efforts may be most beneficial. Here, we used light-level geolocators to track individual Cerulean Warblers from a breeding population in Indiana, USA, and describe their migration routes, stopover sites, and nonbreeding dispersion.

\section{Methods}

We studied Cerulean Warblers at the $\sim 3600$ ha Hardwood Ecosystem Experiment in Indiana, USA $\left(39.114^{\circ} \mathrm{N},-86.322^{\circ}\right.$ W). We captured Cerulean Warblers by luring territorial adult males into mist-nets using broadcasts of conspecific songs and calls. We attached geolocators (P30Z11-7DIP-NOT [0.36 g] \& W50Z11-DIP-NOT [0.45 g] Migrate Technologies Ltd., Cambridge, UK) to 30 individual adult male Cerulean Warblers during June 2016-2018 (Table $\left.1 ; n_{2016}=9, n_{2017}=10, n_{2018}=11\right)$ using a modified leg-loop harness (Fig. 1) [7, 11]. We also monitored a control group of adult male Cerulean Warblers each year (Table 1; $n_{2016}$ $=4, n_{2017}=16, n_{2018}=12$ ), which we captured and marked with unique combinations of color bands, but not with geolocators. We searched for and captured returning geolocator-marked individuals to retrieve geolocators, and we searched for returning control individuals from MayJune in each year after geolocator deployment. To test for possible effects of geolocators on Cerulean Warblers, we used a chi-square test to compare the apparent number of returning geolocator-marked individuals to the apparent number of returning individuals from the control group. We used a Student's $t$-test to test for differences between seasonal migration route lengths, and for differences between seasonal migration speeds.

\subsection{Data Analysis}

We analyzed light-level geolocator data in $\mathrm{R}$ (v. 3.5.1) [12] using the template-fit method of light-level geolocator data analysis in FLightR (v. 4.9) [13] which derives location estimates using the timing and slope of transition events (i.e., sunrises and sunsets). We used the package BAStag [14] to identify transition events (i.e., sunrises and sunsets) in log-transformed light data using a threshold value of $\log (1.5)$ except in one case in which we used $\log (4)$ to avoid misclassification with increased noise in nighttime light levels [15]. We calibrated geolocator data in FlightR using transitions recorded one day following deployment to 1 August. If geolocators were recording data during spring migration when individuals returned to the breeding site, we included an additional calibration period spanning apparent breeding-site arrival to recapture. We analyzed raw geolocator data following the workflow of Rakhimberdiev et al. [15] and using the movement model in FlightR (optimized with one million particles) to derive location estimates (with associated uncertainty) for each twilight throughout the year (including periods around the equinoxes). We used a behavioral mask, which allowed migrating Cerulean Warblers to use over-water routes, but prevented them from being stationary $>25 \mathrm{~km}$ from land. We also constrained the maximum distance between two subsequent twilights to $1200 \mathrm{~km}$ to limit the effects of erroneous location estimates and used the

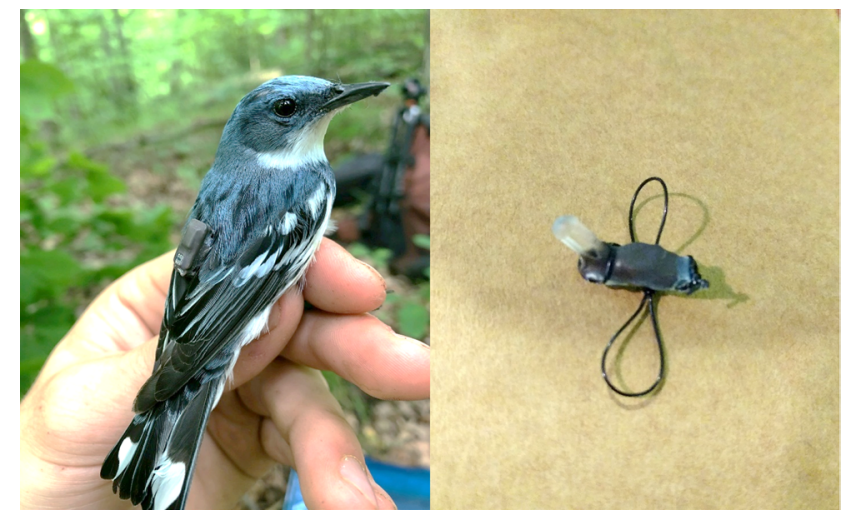

Fig. 1. Adult male Cerulean Warbler (Setophaga cerulea) marked with a light-level geolocator (model P30Z11-7-DIP-NOT; left). Geolocator (with light stalk; model W50Z11-DIP-NOT; right) and harness that goes around an individual's legs allowing the geolocator to sit on the bird's synsacrum. Geolocators were manufactured by Migrate Technologies Ltd. (Cambridge, UK).

Table 1. Apparent returns of Cerulean Warblers marked with geolocators ("Geolocator") and color-bands ("Control") at a breeding site in Indiana, USA $\left(39.114^{\circ} \mathrm{N},-86.322^{\circ} \mathrm{W}\right)$ during $2016-2018$. Number of returning individuals that were recaptured is noted in parentheses.

\begin{tabular}{lllll}
\hline & Geolocator & Control & \\
\hline Year & Marked & Returned (Recaptured) & Marked & Returned \\
2016 & 7 & $2(1)$ & 6 & 2 \\
2017 & 10 & $2(2)$ & 16 & 3 \\
2018 & 11 & $1(1)$ & 12 & 1 \\
\hline
\end{tabular}


built-in automatic outlier exclusion to eliminate extreme location estimates on-the-fly during the movement modeling process [14]. Resulting migration tracks and core nonbreeding areas were not meaningfully different from results derived from model runs without automatic outlier exclusion, without a behavioral mask, or without both features except for one case (Bird A) in which the estimated autumn migration track was affected by the automatic outlier exclusion (the Authors, unpublished data). In this one case, the migration track resulting from a model run with automatic outlier exclusion suggested an eastern route through Florida and the Caribbean, whereas the track from a model run without automatic outlier exclusion suggested a more biologically likely track in which the bird directly crossed the Gulf of Mexico (i.e., the model identified the trans-Gulf movement as an outlier). We report the results from the model without automatic outlier exclusion (i.e., trans-Gulf route) because it is more biologically likely and is consistent with results derived from simpler analytical methods (i.e., those described by Kramer et al. [8]). We used the function stationary. migration.summary in FlightR to estimate the location and duration of stopovers (cutoff probability $=0.2$, minimum stopover $=2$ days) and displayed migration routes with stopover sites as the median location estimate for each twilight [13]. We estimated the onset and commencement of autumn and spring migrations using the function find. times.distribution in FlightR (see code in data depository) $[13,16]$. We estimated migration-route length for individual Cerulean Warblers by summing the Great-Circle distance of migration routes estimated by FlightR. To calculate the minimum average migration speed, we divided the estimated migration-route length of individual Cerulean Warblers by the duration of migration (i.e., number of days from onset of migration to termination of migration). To derive estimates of nonbreeding location (i.e., nonbreeding sites) for individuals, we created probability density functions using all transitions spanning the nonbreeding period (1 November-28 February, or until tag failure) and extracted the coordinates of the maximum likelihood cell (i.e., core nonbreeding area) [8]. Some migratory species use multiple nonbreeding sites throughout the nonbreeding period [e.g. 17, 18]. Based on published accounts of the nonbreeding ecology of Cerulean Warblers, we did not expect Cerulean Warblers to use multiple nonbreeding sites during the nonbreeding period [19]. However, we did not constrain our movement models during the nonbreeding period to allow for the possibility that Cerulean Warblers might use multiple, geographically distinct nonbreeding sites throughout the nonbreeding period.

\section{Results}

Between 2017-2019 we retrieved geolocators from four individuals and resighted 6 control birds (Table 1). Two of the returning geolocator-marked individuals in 2017 were recaptured without their geolocators. However, they showed no signs of carrying a geolocator for a meaningful period (i.e., had no signs of wear on feathers, no callous on skin) and we therefore placed them in the control group for all further analyses as we determined they likely dropped their geolocators shortly after being marked in 2016. We found no evidence for differences in apparent return rates between geolocator-marked Cerulean Warblers and those marked only with colored leg bands (i.e., individuals in the control group; $\chi^{2}[1, n=73]=0.003$, $P=0.99$ ).

Geolocator-marked male Cerulean Warblers $(n=4)$ from Indiana, USA, occurred broadly throughout northern South America during the nonbreeding period (Fig. 2). The distance between the estimated core nonbreeding areas of individuals (i.e., highest probability cell in the probability density function) ranged from $\sim 400-1800 \mathrm{~km}$. Individuals were apparently resident at a single site throughout the nonbreeding period or movements were local and impossible to identify given the inherent spatial limitations of geolocators. We found no evidence of Cerulean Warblers travelling greater distances in spring $\left(\overline{\mathrm{x}}_{\text {spring }}=5107 \pm 171 \mathrm{~km}\right)$ than autumn ( $\left.\overline{\mathrm{x}}_{\text {autumn }}=5482 \pm 1163 \mathrm{~km} ; t=-0.54, P=0.54\right)$ (Table 2). We did find evidence that Cerulean Warblers traveled faster in spring $(141 \pm 8 \mathrm{~km} / \mathrm{d})$ than during autumn migration $(90.5 \pm 26 \mathrm{~km} / \mathrm{d} ; t=-3.15, P=0.03)$.

Cerulean Warblers began autumn migration in August and arrived at nonbreeding sites in South America in late-September to mid-October. Cerulean Warblers made overwater flights across the Gulf of Mexico $(n=2$; Fig. 2A-B) or the Atlantic Ocean and Caribbean Sea $(n=2$; Fig. 2C-D) during autumn migration (Table 2). During autumn migration, neither individual $(n=2)$ stopped over prior to crossing the Gulf and one Cerulean Warbler stopped over after crossing the Gulf (Fig. 2A).

Individuals with geolocators that recorded data during spring migration $(n=3)$ departed nonbreeding areas in mid- to late-March and arrived on breeding territories in late-April or early-May. All geolocator-marked Cerulean Warblers crossed the Gulf of Mexico during spring migration $(n=3)$. Of the three geolocator-marked Cerulean Warblers that recorded data during spring migration, one stopped over along the southern coast of the Gulf of Mexico before crossing the Gulf, but did not stop over after (Fig. 2D), one did not stop over before crossing the Gulf but stopped over on the northern Gulf coast after crossing 
Table 2. Characteristics of autumn and spring migration derived from geolocator data collected from adult male Cerulean Warblers (Setophaga cerulea; $n=4)$ from a breeding site in Indiana, USA $\left(39.114^{\circ} \mathrm{N},-86.322^{\circ} \mathrm{W}\right)$ during $2016-2019$. Onset and end of migration were determined from longitudinal deviations from breeding and nonbreeding sites if movements occurred during or near an equinox. We estimated the timing of migration and stopovers using find.times.distribution and stationary.migration.summary functions in FLightR [14]. Migration distance is the distance travelled $(\mathrm{km})$ along the highest probability seasonal migration routes estimated in FLightR (Fig. 2). Minimum average migration speed is the minimum average speed at which these birds migrated; calculated by dividing the migration distance by the total duration of migration.

\begin{tabular}{llllllll}
\hline & \multicolumn{2}{l}{ Autumn migration } & & & \multicolumn{2}{l}{ Spring migration } \\
\hline Individual & A & B & C & D & B & C & D \\
\hline Year & 2016 & 2017 & 2017 & 2018 & 2018 & 2018 & 2019 \\
Onset of migration & 23 Aug & 8 Aug & 29 Aug & 13 Sep & 16 Mar & 21 Mar & 22 March \\
End of migration & 17 Oct & 10 Oct & 12 Oct & 23 Nov & 24 Apr & 1 May & 28 April \\
Migration distance (km) & 6807 & 4891 & 4274 & 4456 & 5679 & 5395 & 5372 \\
Total duration (days) & 55 & 63 & 44 & 71 & 39 & 41 & 37 \\
Minimum average migration speed (km/d) & 124 & 78 & 97 & 63 & 146 & 132 & 145 \\
Number of stopovers $\geq 2$ days & 3 & 1 & 3 & 4 & 1 & 2 & 1 \\
Average distance between stopovers (km) (SD) & $918(52)$ & NA & $838(520)$ & $862(187)$ & NA & 1209 & NA \\
Average stopover duration (days) (SD) & $7.3(5.8)$ & $18(\mathrm{NA})$ & $7.0(2.6)$ & $15.5(17.9)$ & 11 (NA) & 7.5 (0.7) 13 (NA) \\
Total duration of stopovers (days) & 22 & 18 & 21 & 62 & 11 & 15 & 13 \\
\hline
\end{tabular}

(Fig. 2B), and one bird used stopover sites near the Gulf coast both before and after crossing (Fig. 2C).

Cerulean Warblers made an average of 2.8 stopovers (range: $1-4 ; n=4$ individuals) consisting of $>2$ days during autumn migration, and 1.3 stopovers (range: 1-2; $n=3$ individuals) consisting of $>2$ days during spring migration. Stopover duration averaged 12.0 days (range: 7-18; $n=11$ ) in autumn and 10.5 days (range: 7.5-13; $n=4$ ) in spring (Table 2).

\section{Discussion}

Although our sample size is modest, we did not detect any evidence that geolocators affected the apparent return rate of Cerulean Warblers to our breeding site in Indiana. Other studies tracking small songbirds using identical geolocator attachment methods found no evidence that geolocators affect apparent return rates [e.g., 6]. Using a slightly different attachment method, Raybuck et al. [20] reported a negative effect of geolocators on the apparent return rate of geolocator-marked Cerulean Warblers [but see 21]. Ultimately, the lack of evidence for geolocator effects in our study suggests that our results likely represent an unbiased sample of the migratory behavior of adult male Cerulean Warblers breeding in our study area; however, future efforts to study Cerulean Warblers with geolocators should continue monitoring for any effects of geolocators on survival or other fitness parameters [22].

Geolocator-marked male Cerulean Warblers breeding in Indiana, USA, occurred in geographically distinct areas during the nonbreeding period. Although it is impossible to determine the strength of migratory connectivity of a species using data from a single population, our observations of broad nonbreeding dispersion of a single population suggest Cerulean Warblers may be unlikely to exhibit strong migratory connectivity (i.e., geographic isolation among migratory populations throughout the annual cycle) if other populations exhibit similar levels of individual dispersion during the nonbreeding period [1]. Strong migratory connectivity has been described in some Nearctic-Neotropical migratory species such as Goldenwinged Warblers (Vermivora chrysoptera) [3]. If Cerulean Warblers exhibited similarly strong migratory connectivity, we may not expect to see such broad dispersion of individuals from a singular breeding site throughout the known nonbreeding distribution $[1,3]$. Weak migratory connectivity (i.e., broad overlap among isolated breeding populations during the nonbreeding period) appears to be the more common strategy among migratory bird species [1, 23]. Blue-winged Warblers (V. cyanoptera) [3] are one species that exhibit weak migratory connectivity with population dispersion similar to what we observed in our population of Cerulean Warblers. Weak migratory connectivity can buffer populations from limiting factors occurring at local nonbreeding areas [1]. 

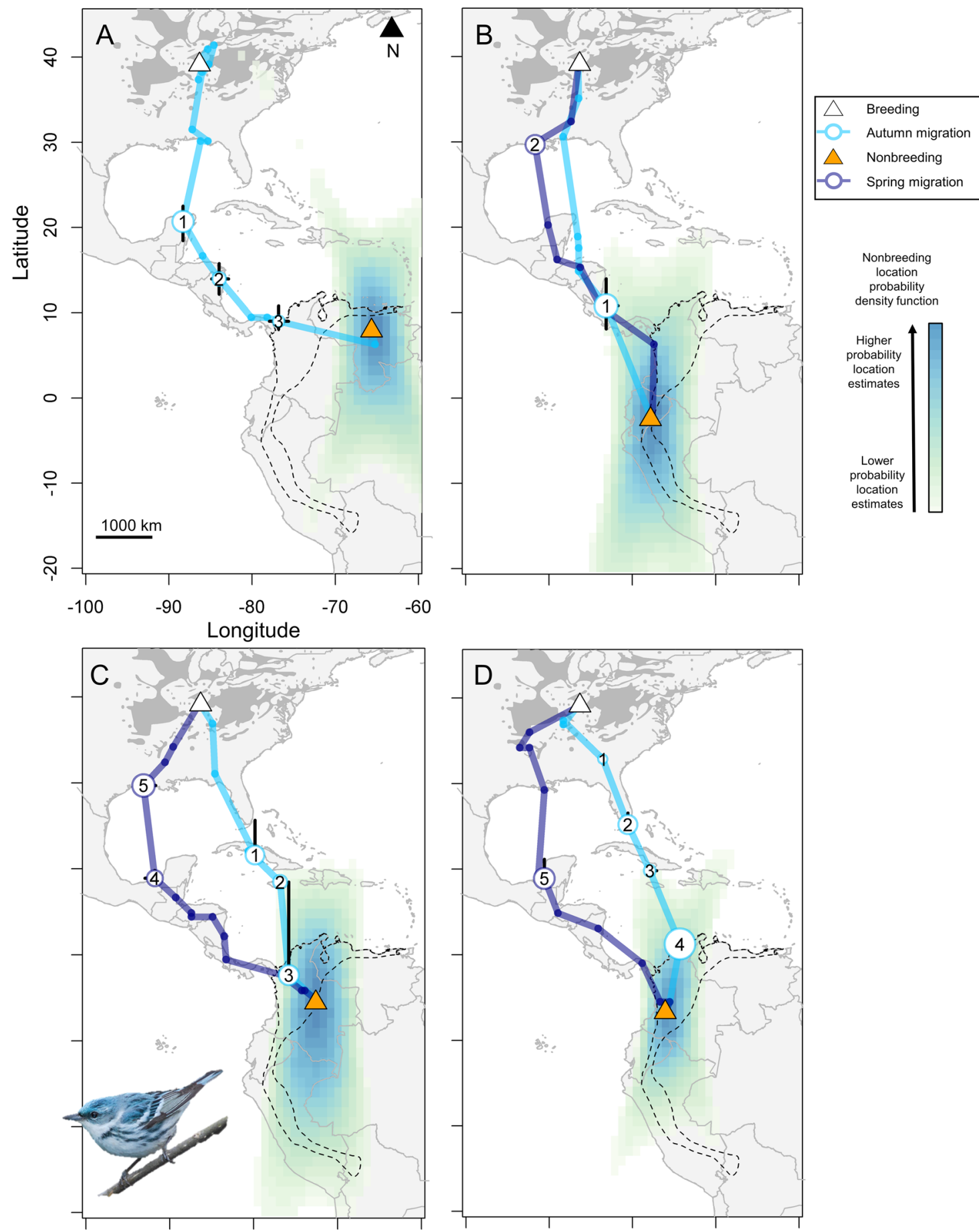

Fig. 2. Interpolated migration routes and nonbreeding location estimates derived from geolocator data from individual adult male Cerulean Warblers (Setophaga cerulea; $n=4)$ marked at a breeding site in Indiana, USA (39.114 ${ }^{\circ} \mathrm{N},-86.322^{\circ} \mathrm{W}$; white triangle) during $2016-2018$. In all panels, colored lines track the median location estimates during autumn (light blue) and spring (purple) migrations. Stopover sites are represented by sequentially numbered circles and are areas that individuals were determined to be present for $\geq 2$ days. The size of the circle relative to the duration of stopover with larger circles representing stopovers of greater duration. Error in stopover location estimates are represented by black whiskers $(95 \% \mathrm{Cl}$ ) around stopover sites (not visible when stopover point is larger than $95 \% \mathrm{Cl}$ ). Small, colored dots identify locations used by individuals for $<2$ days during autumn (light blue) and spring (purple) migration. The nonbreeding probability density function for each individual during the nonbreeding period for the duration of the nonbreeding period (or from nonbreeding site arrival until tag failure) is presented with darker blue representing more likely location estimates (cells $<75 \%$ of maximum probability are not shown). The highest probability location estimate for the nonbreeding period is identified (orange triangle). The Cerulean Warbler breeding range is represented by dark gray shading and the nonbreeding range is delineated by a dashed line. Cerulean Warbler photo courtesy of Wikimedia Commons/Mdf via CC BY-SA 3.0 license. 
However, nonbreeding factors can still drive regional breeding population declines in species exhibiting weak connectivity if the limiting factors are broadly occurring or widespread across the nonbreeding distribution [e.g., 24]. Unlike some species with migratory divides and strong migratory connectivity (e.g., Golden-winged warblers [3]; Swainson's Thrushes [Catharus ustulatus] [25]), Cerulean Warbler declines are largely consistent across the breeding distribution [5]. Combined with the level of nonbreeding dispersion we observed in Cerulean Warblers breeding in Indiana, USA, the lack of geographic variation in population declines may be further evidence of relatively weak migratory connectivity in Cerulean Warblers and suggests range-wide population declines may be linked to extensive habitat loss or degradation across the entire nonbreeding distribution [3, 24] or expansive portions of the breeding distribution.

To the best of our knowledge, our results represent the only published account of the migratory patterns of individual Cerulean Warblers throughout the annual cycle. However, an unpublished analysis of geolocators recovered from five Cerulean Warblers marked at breeding sites in Pennsylvania, USA, $(n=4)$ and Missouri, USA, $(n=$ 1) reported individuals marked in Pennsylvania wintered in northern Colombia or northwest Venezuela, whereas an individual marked in Missouri wintered in Peru [26]. Additional information from populations throughout the breeding distribution of Cerulean Warblers will therefore be important in determining the level of migratory connectivity among distinct breeding population segments and the nature of limiting factors driving regional population trends [3]. For Cerulean Warblers breeding in Indiana, USA, the broad dispersion and lack of geographic overlap among individuals during the nonbreeding period suggest population dynamics in this population may be more sensitive to limiting factors occurring at shared breeding sites or conditions experienced along common migratory routes and stopover sites than at nonbreeding sites.

Cerulean Warblers are thought to migrate directly across the Gulf of Mexico during both autumn and spring migrations [9]. Our observations confirm trans-Gulf migratory flights by some individuals during both autumn and spring migrations. Welton et al. [27] and Parker [28] found that areas along the southern coast of the Gulf of Mexico (Guatemala and the Yucatan Peninsula) and northern Central America (Honduras) represented important stopover areas for Cerulean Warblers during spring migration, as a significant portion of the global population may stop in this small geographic area to refuel before crossing the Gulf of Mexico. Interestingly, we observed variation in stopover behavior of Cerulean Warblers before and after prolonged migratory flights (i.e., trans-Gulf flights). Some individuals stopped over before, and after crossing the Gulf of Mexico whereas some stopped over before, or after crossing the Gulf of Mexico. These results suggest that the stopover behavior of individual Cerulean Warblers may be more variable than previously thought [27]. Recent findings from other migratory species suggest an individual's fuel load may influence its subsequent stopover behavior [e.g., 29]. Similarly, conditions experienced during prolonged migratory flights may influence the subsequent stopover behavior of migratory individuals [30]. Our results suggest that individual migrating Cerulean Warblers may not require stopovers to rest and refuel following prolonged migratory flights. Future efforts should explore the relationship between Cerulean Warbler stopover behavior and endogenous (e.g., fuel stores) and exogenous (e.g., weather) conditions. Additional data from other populations and during different years may also help determine the importance of the Gulf of Mexico region as critical stopover habitat for Cerulean Warblers and will help document the frequency with which Cerulean Warblers use migration routes and stopover sites away from the Gulf of Mexico (Fig. 2C-D).

Identifying limiting factors associated with severe population declines across the Cerulean Warbler breeding distribution will require information on the distribution of individuals from other populations throughout the annual cycle. However, our results suggest that Cerulean Warblers may be likely to exhibit relatively weak migratory connectivity in which breeding populations co-occur in nonbreeding regions. Thus, breeding populations of Cerulean Warblers may be buffered against acute, regionally isolated, limiting effects occurring during the nonbreeding period (e.g., deforestation, disease, habitat degradation). Future efforts to examine migratory routes and nonbreeding sites of Cerulean Warblers across their range, including in populations outside the core of the breeding distribution will be useful for informing effective full-annual cycle conservation strategies and will also provide important information for understanding the evolutionary and ecological implications of migratory connectivity in Cerulean Warblers and other species.

Acknowledgements: We thank field technicians E. Chen, L. Brouellette, K. Pangman, L. Dargis, and S. CarreraLozano for their hard work. We also thank H. Streby for helpful discussions of geolocator attachment methods. In addition, we thank one anonymous reviewer and Andrew Davis for helpful comments on this manuscript. 
Funding: This research was supported by the Indiana Department of Natural Resources through Purdue University, Amos W. Butler Audubon Society, Geoff and Josie Fox Student Grant through Robert Cooper Audubon Society, Indiana Academy of Science, and Ball State University’s ASPiRE grant.

Author contributions: $\mathrm{CDD}$ and $\mathrm{KI}$ conceived and designed the study. GRK performed the statistical analyses. CDD and KI obtained funding for this research. CDD and GRK wrote the manuscript. CDD, GJM, ARS, and BMC deployed and collected geolocators in the field. All authors reviewed and edited drafts of the manuscript.

Ethics approval/permitting: All research activities complied with all state and federal laws. Cerulean Warblers were captured and banded under permits issued by the Indiana Department of Natural Resources and the U.S. Geological Survey, Bird Banding Laboratory (Permit \#21781). Animal welfare and handling protocols were approved by Ball State Institutional Animal Care and Use Committee (approval 437484-4).

\section{References}

[1] Webster S.M., Marra P.P., Haig S.M., Bensch S., Holmes R.T., Links between worlds: Unraveling migratory connectivity, Trends Ecol. Evol., 2002, 17, 76-83

[2] Hewson C.M., Thorup K., Pearce-Higgins J.W., Atkinson P.W., Population decline is linked to migration route in the Common Cuckoo. Nat Comm., 2016, 7, 12296

[3] Kramer G.R., Andersen D.E., Buehler D.A., Wood P.B., Peterson S.M., Lehman J.A., et al., Population trends in Vermivora warblers are linked to strong migratory connectivity, Proc. Natl. Acad. Sci. U.S.A., 2018, 115, E3192-3200

[4] McKinnon E.A., Love O.P., Ten years tracking the migrations of small landbirds: Lessons learned in the golden age of bio-logging, Auk, 2018, 135, 834-856

[5] Sauer, J.R., Niven D.K., Hines J.E., Ziolkowski D.J., Pardieck Jr, K.L., Fallon J.E., et al., The North American Breeding Bird Survey, Results and Analysis 1966-2015, Version 2.07.2017, USGS Patuxent Wildlife Research Center, Laurel, MD, USA, 2017

[6] Peterson S.M., Streby H.M., Kramer G.R., Lehman J.A., Buehler D.A., Andersen D.E., Geolocators on Golden-winged Warblers do not affect migratory ecology, Condor, 2015, 117, 256-261

[7] Streby H.M., McAllister T.L., Peterson S.M., Kramer G.R., Lehman J.A., Anderson D.E., Minimizing marker mass and handling time when attaching radio-transmitters and geolocators to small songbirds, Condor, 2015, 117, 249-255

[8] Kramer G.R., Streby H.M., Peterson S.M., Lehman J.A., Buehler D.A., Wood P.B., et al., Nonbreeding isolation and population-specific migration patterns in three populations of Golden-winged Warblers, Condor, 2017, 119, 108-121
[9] Buehler D.A., Giocomo J.J., Jones J., Hamel P.B., Rogers C.M., Beachy T.A., et al., Cerulean Warbler reproduction, survival, and models of population decline, J. Wildl. Manage., 2008, 72, 646-653

[10] Weakland C.A., Wood P.B., Cerulean Warbler (Dendroica cerulea) microhabitat and landscape-level habitat characteristics in southern West Virginia, Auk, 2005, 122, 497-508

[11] Rappole J.H., Tipton A.R., New harness design for attachment of radio transmitters to small passerines, J. Field Ornithol., 1991, $62,335-337$

[12] R Core Team, R: A language and environment for statistical computing. R Foundation for Statistical Computing, Vienna, Austria, 2018

[13] Rakhimberdiev E., Saveliev A., Piersma T., Karagicheva J., FLightR: an R package for reconstructing animal paths from solar geolocation loggers, Methods Ecol. Evol., 2017, 8 , 1482-1487

[14] Wotherspoon S., Sumner M., Lisovski S., BAStag: Basic data processing for light based geolocation archival tags, $\mathrm{R}$ Package version 0.1-3, 2013

[15] Rakhimberdiev E., Senner N.A., Verhoeven M.A., Winkler D.W., Bouten W., Piersma, T., Comparing inferences of solar geolocation data against high-precision GPS data: Annual movements of a double-tagged Black-tailed Godwit, J. Avian Biol., 2016, 47, 589-596

[16] Delancey C., Cerulean Warbler Geolocator Analysis, Figshare, Dataset, 2020, https://doi.org/10.6084/m9.figshare.11958975. v1

[17] Knight S.M., Bradley D.W. Clark R.G., Gow E.A., Bélisle M., Berzins L.L, et al., Constructing and evaluating a continentwide migratory songbird network across the annual cycle, Ecol. Mono., 2018, 88, 445-460

[18] Imlay T.L., Hobson K.A., Roberto-Charron A., Leonard M.L., Wintering areas, migratory connectivity and habitat fidelity of three declining Nearctic-Neotropical migrant swallows, Ani. Mig., 2018, 5, 1:16

[19] Bakermans M.H., Vitz A.C., Rodewald A.D., Rengifo C.G., Migratory songbird use of shade coffee in the Venezuelan Andes with implications for conservation of Cerulean Warbler, Biological Conservation, 2009, 142, 2476-2483

[20] Raybuck D.W., Larkin J.L., Stoleson S.H., Boves T.J., Mixed effects of geolocators on reproduction and survival of Cerulean Warblers, a canopy-dwelling, long-distance migrant, Condor, 2017, 119, 289-297

[21] Streby H.M., Kramer G.R., Comment on "Mixed effects of geolocators on reproduction and survival of Cerulean Warblers, a canopy-dwelling, long-distance migrant”, Condor, 2017, 119 , 848-514

[22] Taff C.C., Freeman-Gallant C.R., Streby H.M., Kramer G.R., Geolocator deployment reduces return rate, alters selection, and impacts demography in a small songbird, PLOS ONE, 2018, 13, E0207783

[23] Finch T., Butler S.J., Franco A.M.A., Cresswell W., Low migratory connectivity is common in long-distance migrant birds, J. Anim. Ecol., 2017, 86, 662-673

[24] Taylor C.M., Stutchbury B.J.M, Effects of breeding versus wintering habitat loss and fragmentation on the population dynamics of a migratory songbird, Ecol. Appl., 2015, 26, 424-437 
[25] Delmore K.E., Fox J.W., Irwin D.E., Dramatic intraspecific differences in migratory routes, stopover sites and wintering areas, revealed using light-level geolocators, Proc. R. Soc. B., 2012, 279, 1747

[26] Raybuck D.R., Migration and the post-fledging period: examining two critical stages of the Cerulean Warbler life cycle, MS Thesis, Arkansas State University, Jonesboro, AR, 2016

[27] Welton M.J., Anderson D.L., Colorado G.J., Hamel P.B., Calderon-F D., Spring migration stopover by Cerulean Warblers in northern Middle America, Ornitol. Neotrop., 2012, 23, 289-305
[28] Parker, III, T.A., Habitat, behavior, and spring migration of Cerulean Warbler in Belize, Am. Birds, 1994, 48, 70-75

[29] Gómez C., Bayly N.J., Norris D.R., Mackenzie S.A., Rosenberg K.V., Taylor P.D., et al., Fuel loads acquired at a stopover site influence the pace of intercontinental migration in a boreal songbird, Sci. Rep., 2017, 3405

[30] Deppe J.L., Ward M.P., Bolus R.T., Diehl R.H., Celis-Murillo A., Zenzal, Jr., et al., Fat, weather, and date affect migratory songbirds' departure decisions, routes, and time it takes to cross the Gulf of Mexico, Proc. Natl. Acad. Sci., 2015, E6331-E6338 